\title{
Can anthropometric, body composition, and bone variables be considered risk factors for musculoskeletal injuries in Brazilian military students?
}

\author{
Mauro A. S. Melloni* (D), Josiel De Almeida Ávila, Mauro Alexandre Páscoa, Camila Justino De Oliveira Barbeta, \\ Vagner Xavier Cirolini, Ezequiel M. Gonçalves and Gil Guerra-Júnior
}

\begin{abstract}
Background: Musculoskeletal injuries are the main cause of premature discharge from military service and can sometimes lead to permanent disabilities. Some intrinsic risk factors are well discussed in the literature. However, the relation between body composition variables and the risk for musculoskeletal injury is not well known or recognized.

Methods: This prospective study evaluated 205 Brazilian military students. At the beginning of military service, health status and sports experience prior to military service were registered. Anthropometric variables were evaluated, and bone and body composition variables were measured using dual-energy X-ray absorptiometry. The occurrence of musculoskeletal injuries throughout the year was registered at the military physiotherapy service. At the end of 1 year of follow-up, risk factors were analysed by comparing the variables between the injured and non-injured students.

Results: No difference in previous health status was found between injured and non-injured groups, whereas sports experience prior to military service was identified as a protective factor (Odds Ratio (OR) 0.323; 95\% Cl: $0.108-0.968 ; p=0.044)$. Anthropometric, bone, and body composition variables could not be identified as risk factors for musculoskeletal injuries in Brazilian military students.

Conclusion: Anthropometric, bone, and body composition variables could not be considered risk factors for musculoskeletal injuries in Brazilian military students.
\end{abstract}

Keywords: Military, cumulative trauma disorders, body composition, risk factors

\section{Background}

Being healthy and physically fit is required in the military profession. Thus, some aspects of military physical training programs are important to ensure development of the physical and fitness skills required in the military profession. However, they can also lead to musculoskeletal injury (MI) and disabilities, which in turn result in premature discharge from military service $[1,2]$. In this respect, a systematic review [2] showed a cumulative incidence

\footnotetext{
* Correspondence: mauromelloni@gmail.com

Departamento de Pediatria, Universidade Estadual de Campinas-Unicamp, Tessália Vieira de Camargo, 126, Cidade Universitária Zeferino Vaz, Campinas, SP Zip code: 13083-887, Brazil
}

ranging from 8 to $51 \%$ for MI related to military physical training, whereas a prospective study reported that almost $70 \%$ of participants followed up for 6 months presented with at least one type of MI, [3] concluding that MI is an important public health problem for the military.

The literature on general military health usually recognizes that overload injuries are more prevalent than traumatic injuries in the military population [4]. Furthermore, MI is highlighted as the main cause of premature discharge from military service [5] and the main reason for seeking medical care during the service [1]. Consequently, premature discharge from military service and the need for medical care owing to MI can result in 
financial and physical fitness losses and psychological changes, mainly in countries where military service is compulsory [5].

Many variables are reported as risk factors for MI related to military physical training. In general, these variables are usually classified as extrinsic (e.g. long weekly running distance, absence of sports experience prior to military service, smoking habit, and history of MI prior to military service) $[5,6]$ or intrinsic (e.g. low physical fitness, low educational level, large abdominal girth, high body mass index [BMI], and low body mass) [3-5].

Previous military studies have sought to identify anthropometric characteristics as risk factors for MI related to physical training. Those studies observed that BMI [3-5, 7] and waist circumference [3] were potential risk factors for MI. Thus, as the literature has selected anthropometric variables as risk factors, we hypothesized that a more specific body composition assessment can provide information regarding the predictive value of body components as risk factors for injuries in militaries.

In this regard, a Greek study that measured body fat percentage using bioelectrical impedance analysis confirmed the hypothesis by observing that adiposity expressed as body fat percentage can predict the risk for MI in militaries [8]. However, a glance at the literature exposes the current gap on this topic, because there are few studies that have investigated body composition variables as risk factors for MI. For example, to our knowledge no recent studies have measured fat-free mass, bone mineral content (BMC), and bone mineral density (BMD) to investigate the risk factors for MI in militaries. In this respect, dual-energy X-ray absorptiometry (DXA) is a well-adopted method to evaluate body composition in different populations, including children and adolescents, [9-11] individuals with different diseases [12] athletes, [13, 14] and also militaries, [15] mainly because it is considered non-invasive and fast and involves low radiation exposure [16-18]. Furthermore, another advantage of this method is that it can evaluate total or segmental (right and left sides of the upper and lower limbs and trunk) fat mass, BMC, and lean soft tissue as separate compartments with good accuracy and reliability [16-18], which can provide information regarding imbalances among different body tissues and segments. These imbalances can supposedly represent an additional risk for MI, as observed by a study on rugby athletes [19]. In that study, lower BMD, lower fat-free mass, higher fat mass, and higher body mass were considered risk factors for bone injuries [19]. Furthermore, considering that comparative tests have identified imbalances in limb performance as risk factors for MI [20, 21], we believe that it is important to investigate if there are relationships between body composition imbalance in terms of limbs and the risk of injury. To our knowledge, this has not been investigated, especially using DXA. On the other hand, despite several advantages and the accuracy of DXA, its high cost and the need to visit specific research centres for evaluation may explain why few studies have adopted this method for investigating the risk factors for MI.

Thus, considering the fact that there are many studies focusing on the investigation of anthropometric variables as risk factors for MI in different populations, no studies have used DXA in militaries for the investigation of body composition as a risk factor for MI, this study aimed to verify the prevalence of $\mathrm{MI}$ in military students and to investigate the effect of total and segmental body composition assessed by DXA on the risk for MI in military students at the end of 1 year of military service.

\section{Methods}

This was a prospective study with a follow-up period of 9 months (from March to November 2013). The participants were military students from Escola Preparatória de Cadetes do Exército located in Campinas, São Paulo, Brazil. This school is responsible for the first year of study of cadets in the Brazilian army and annually receives 500 students approved in a public contest under a boarding school regime. The first 205 male students who agreed to participate in this study were included in a convenience sample. The inclusion criteria were recent inclusion in the army during the study period and the absence of any physical complaint or MI at the baseline evaluation at the beginning of military service. The study was approved by the ethics committee of the faculty of medical science of the Unicamp ( ${ }^{\circ}$ 511.4610).

\section{Baseline measurements}

Participants underwent health status and body composition evaluation at the beginning of service in March 2013. Prior evaluation was performed at the Laboratory of Growth and Development in the Pediatric Investigation Center, University of Campinas, Campinas, São Paulo, Brazil. Participants were required to fill out a questionnaire that assessed demographic data and other potential risk factors such as history of chronic disease and MI prior to military service and physical activity experience.

Body mass was measured using a balance-beam scale $\left(\right.$ Filizola $\left.{ }^{\mathrm{mm}}\right)$ with a precision of $100 \mathrm{~g}$ that was graduated from 0 to $150 \mathrm{~kg}$. Height was measured using a stadiometer (Holtain Ltd. ${ }^{\mathrm{mm}}$ ) with a precision of $1 \mathrm{~cm}$. BMI was calculated using the formula weight/height ${ }^{2}$. 


\section{Body composition and bone variables}

Body composition and bone variables were measured using DXA (model iDXA, GE Healthcare Lunar, Madison, WI, USA). Fat mass $(\mathrm{kg})$ and relative fat mass $(\%)$, BMC $(\mathrm{kg})$, fat-free mass $(\mathrm{kg})$, and $\mathrm{BMD}\left(\mathrm{g} / \mathrm{cm}^{2}\right)$ were estimated. In order to maximize the investigation on risk factors, we analysed the data for total and segmental (right and left sides of the lower and upper limbs and trunk) body composition and bone variables.

\section{Training routine and injury registration}

After baseline evaluation, participants started the military physical training program proposed and coordinated by the military school. This program comprised five weekly training sessions that each lasted for $1 \mathrm{~h}$ and $30 \mathrm{~min}$. After some training sessions, according to their sporting abilities, some participants were selected to form school sports teams that would represent the military school in Brazilian military competitions. Consequently, a specific training period during the year was planned for some students according to the sports modality that they were recruited for. Sports training and military physical training were conducted at the same period. In case of health complaints, participants sought military school medical service. MI was diagnosed by a military physician and was defined as a musculoskeletal complaint that led to at least one instance of withdrawal from training or competition. In this case, the participant was referred to a military physiotherapy service, and the researcher proceeded with the injury registration. Injuries were classified according to aetiology as traumatic (a known trauma in a specific moment) or overload (non-traumatic mechanisms). At the end of the study period, we proceeded with the investigation on risk factors for general, traumatic, and overload injuries and lower and upper limb injuries (Fig. 1).

\section{Statistical analysis}

Data were analysed using SPSS version 16. KolmogorovSmirnov test was used to verify the normality of data. Independent-samples Student's t-test was used to compare the injured and non-injured militaries. To verify the association between MI and sample characteristics (sports team participation during the study, history of chronic disease or MI prior to military service, and sports experience prior to military service), chi-square test or Fisher's exact test was used. Logistic regression analysis was used to investigate the risk factors for MI, traumatic or overload injuries, and upper or lower limb injuries. The computation of odds ratios was included. The significance level was set at $5 \%$.
225 militaries invited in March 2013

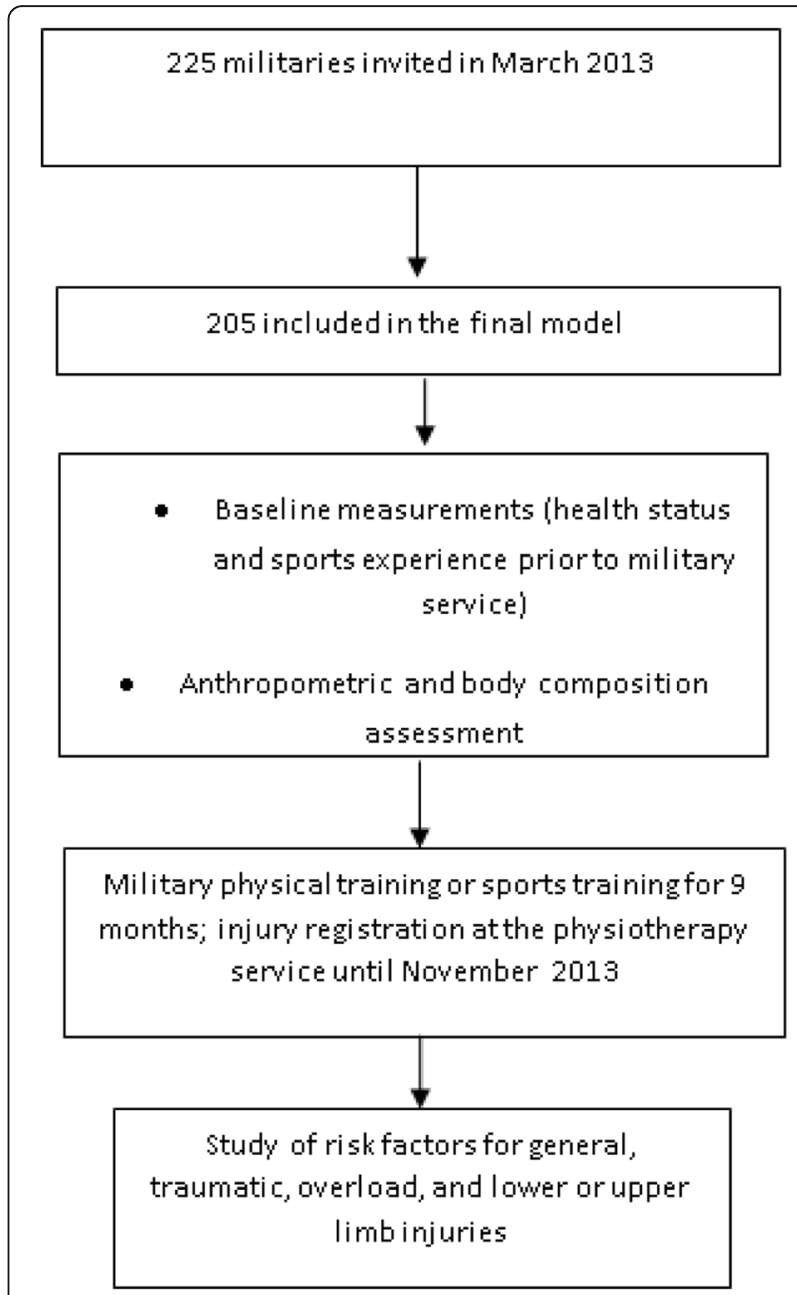

Fig. 1 Study sequence actions. Legend: flow of participants through the study

\section{Results}

During follow-up, 66 injuries were registered in 56 participants $(27.3 \%$ of the sample), with 41 overload injuries (62.1\%) and 25 traumatic injuries (37.8\%). The most prevalent injuries observed were ankle sprain (16.6\%) and medial tibial stress syndrome (15.1\%). Most injuries occurred in the lower limbs (69.7\%), followed by the upper limbs $(25.7 \%)$ and spine (4.5\%). The demographic and descriptive data of the total sample and comparison of anthropometric and body composition variables between the injured and non-injured groups are presented in Table 1. No differences between the injured and non-injured groups were found.

Similarly, no differences in sports team participation during the study (Chi-Square 0,010; $p=0.92$ ), history of chronic disease (Fischer exact $p=0.913$ ) or MI (Chi-Square $=2593 ; p=0.107$ ) prior to military service, and sports experience prior to military service (Fisher 
Table 1 Demographic data of the total sample and comparison of anthropometric and body composition variables between the injured and non-injured groups

\begin{tabular}{|c|c|c|c|c|c|c|c|c|c|}
\hline \multirow[b]{2}{*}{ Variables } & \multicolumn{4}{|c|}{ Total $n=205$} & \multicolumn{2}{|c|}{ Non-injured $n=149$} & \multicolumn{2}{|c|}{ Injured $n=56$} & \multirow[t]{2}{*}{$P$} \\
\hline & $\overline{\text { Mean }}$ & SD & Min & $\operatorname{Max}$ & Mean & SD & $\overline{\text { Mean }}$ & SD & \\
\hline Age (years) & 19.6 & 1.4 & 16.7 & 23.9 & 19.5 & 1.5 & 19.8 & 1.4 & 0.168 \\
\hline Height (cm) & 176.2 & 6.4 & 160.3 & 192.4 & 175.8 & 6.4 & 177.3 & 6.1 & 0.111 \\
\hline Body mass (kg) & 71.3 & 8.1 & 53.8 & 95.5 & 71.3 & 8.5 & 71.2 & 7.0 & 0.889 \\
\hline BMI $\left(\mathrm{kg} / \mathrm{m}^{2}\right)$ & 22.9 & 2.1 & 17.62 & 28.8 & 23.1 & 2.1 & 22.6 & 2.0 & 0.187 \\
\hline $\mathrm{FM}(\mathrm{kg})$ & 12.5 & 3.4 & 5.7 & 22.3 & 12.5 & 3.4 & 12.4 & 3.6 & 0.914 \\
\hline$\% F M$ & 17.2 & 3.7 & 9.7 & 26.1 & 17.2 & 3.5 & 17.2 & 4.1 & 0.979 \\
\hline FFM (kg) & 56.3 & 5.9 & 41.3 & 75.4 & 56.3 & 6.2 & 56.1 & 5.3 & 0.856 \\
\hline $\mathrm{BMC}(\mathrm{kg})$ & 3.0 & 0.4 & 2.2 & 4.2 & 3.0 & 0.4 & 3.0 & 0.4 & 0.916 \\
\hline $\operatorname{BMD}\left(\mathrm{g} / \mathrm{cm}^{2}\right)$ & 1.229 & 0.095 & 0.989 & 1.561 & 1.230 & 0.093 & 1.227 & 0.101 & 0.874 \\
\hline
\end{tabular}

Abbreviations: $S D$ standard deviation, $B M I$ body mass index, $F M$ fat mass, \%FM relative fat mass, $F F M$ fat-free mass, $B M C$ bone mineral content, $B M D$ bone mineral density

exact $p=0.51$ ) were found between the injured and non-injured groups.

Table 2 shows the results of logistic regression analysis to investigate the included variables as risk factors for MI.

Anthropometric variables were not found to be risk factors for MI (height OR $=1.040,95 \% \mathrm{CI}=0.991-1.093$, $p=0.112$; body mass $\mathrm{OR}=0.997,95 \% \mathrm{CI}=0.960-1.036$, $p=0.888 ;$ BMI OR $=0.903,95 \% \mathrm{CI}=0.776-1.051, p=$ $0.187)$. An absence of sports team participation during follow-up and an absence of history of chronic disease or MI prior to military service were not found to be protective factors for MI. In contrast, sports experience prior to military service was found to be a protective factor for $\mathrm{MI}(\mathrm{OR}=0.32$; 95\% CI $0.108-0.968 ; p=0.04)$. Logistic regression analysis for categorical variables are shown in Table 2.

The results of logistic regression analysis to investigate body composition variables as potential risk factors for general, traumatic, and overload injuries are presented in Table 3. None of the studied variables were found to be risk factors.

Finally, Table 4 presents the logistic regression results comparing body composition variables between the

Table 2 Logistic regression analysis of risk factors with respect to general sample characteristics for categorical variables

\begin{tabular}{llllll}
\hline Variables & $\mathrm{B}$ & $\mathrm{SE}$ & $\mathrm{OR}$ & $95 \% \mathrm{Cl}$ OR & $P$ \\
\hline Non-athlete $^{\mathrm{a}}$ & 0.078 & 0.312 & 1.081 & $0.587-1.994$ & 0.802 \\
No disease $^{\mathrm{b}}$ & 0.041 & 0.613 & 1.042 & $0.313-3.465$ & 0.947 \\
No previous injury $^{c}$ & 0.553 & 0.316 & 1.739 & $0.935-3.233$ & 0.080 \\
Sports practice $^{\mathrm{d}}$ & -1.129 & 0.559 & 0.323 & $0.108-0.968$ & 0.044
\end{tabular}

Abbreviations: $B$ beta coefficient of logistic regression, $S E$ standard error, OR odds ratio, $95 \% \mathrm{Cl} 95 \%$ confidence interval, $B M I$ body mass index

anon-athlete during the follow-up

${ }^{b}$ no history of chronic disease prior to the service

cno history MI prior to the service

${ }^{d}$ sports experience prior to military service non-injured group and the group with injury in the lower limbs and between the non-injured group and the group with injury in the upper limbs. Body composition variables were not found to be risk factors.

\section{Discussion}

Our prospective study with a follow-up period of 9 months investigated the prevalence of MI in Brazilian military students. We also sought to identify the risk factors for MI, overload and traumatic injuries, and upper and lower limb injuries. Of the participants, 27.3\% presented with at least one type of $\mathrm{MI}$, and overload injuries were the most prevalent $(62.1 \%)$, with most injuries occurring in the lower limbs (69.7\%). However, none of the studied body composition variables were found to be risk factors for MI, overload and traumatic injuries, or injuries in the lower or upper limbs. Finally, sports experience prior to military service was identified as a protective factor for MI.

The prevalence rate of almost $30 \%$ for MI in our study population reflects that $\mathrm{MI}$ is an important public health problem that deserves attention from military health-care providers, which has already been described by several studies. For example, an Iranian military study with a follow-up period of 1 year observed that MI accounted for $96 \%$ of health problems occurrence in one year of follow-up [1]. Moreover, a Finnish study demonstrated that $10 \%$ of a military sample was prematurely discharged from military service for medical reasons, mainly MI, and that premature discharge from military service was a potential risk factor for psychological problems, primarily in countries where military service is compulsory [22]. The findings of previous studies in the literature highlight the need for preventive strategies based on scientific knowledge about risk factors, considering the physical demands imposed on militaries in service that increase their risk for injury. Although we 
Table 3 Logistic regression analysis to investigate body composition variables as risk factors for general, traumatic, and overload injuries

\begin{tabular}{|c|c|c|c|c|c|c|c|c|c|}
\hline \multirow[b]{2}{*}{ Variables } & \multirow[b]{2}{*}{ OR } & \multicolumn{3}{|c|}{ General (total) } & \multicolumn{3}{|l|}{ Traumatic } & \multicolumn{2}{|l|}{ Overload } \\
\hline & & (95\% Cl OR) & $P$ & OR & (95\% Cl OR) & $P$ & OR & (95\% Cl OR) & $P$ \\
\hline FM\% & 1.00 & $(0.92-1.09)$ & 0.97 & 1.09 & $(0.97-1.23)$ & 0.13 & 0.95 & $(0.84-1.07)$ & 0.84 \\
\hline $\mathrm{FM}(\mathrm{kg})$ & 1.00 & $(0.91-1.09)$ & 0.91 & 1.06 & $(0.94-1.20)$ & 0.30 & 0.95 & $(0.84-1.08)$ & 0.50 \\
\hline $\mathrm{BMC}(\mathrm{kg})$ & 1.04 & $(0.47-2.34)$ & 0.91 & 1.21 & $(0.41-3.53)$ & 0.71 & 0.88 & $(0.28-2.80)$ & 0.8 \\
\hline FFM (kg) & 1.00 & $(0.95-1.05)$ & 0.85 & 0.97 & $(0.90-1.04)$ & 0.46 & 1.01 & $(0.94-1.09)$ & 0.63 \\
\hline $\mathrm{BMD}\left(\mathrm{g} / \mathrm{cm}^{2}\right)$ & 0.77 & $(0.03-19.2)$ & 0.87 & 1.91 & $(0.02-154.6)$ & 0.77 & 0.24 & $(0.00-22.3)$ & 0.5 \\
\hline FM, upper limbs (g) & 1.00 & $(1.00-1.00)$ & 0.81 & 1.00 & $(1.00-1.00)$ & 0.52 & 1.00 & $(0.99-1.00)$ & 0.63 \\
\hline FM, lower limbs (g) & 1.00 & $(1.00-1.00)$ & 0.86 & 1.00 & $(1.00-1.00)$ & 0.30 & 1.00 & $(1.00-1.00)$ & 0.3 \\
\hline FM, trunk (g) & 1.00 & $(1.00-1.00)$ & 0.98 & 1.00 & $(1.00-1.00)$ & 0.33 & 1.00 & $(1.00-1.00)$ & 0.72 \\
\hline FFM, upper limbs (g) & 1.00 & $(1.00-1.00)$ & 0.85 & 1.00 & $(1.00-1.00)$ & 0.85 & 1.00 & $(1.00-1.00)$ & 0.52 \\
\hline FFM, lower limbs (g) & 1.00 & $(1.00-1.00)$ & 0.75 & 1.00 & $(1.00-1.00)$ & 0.50 & 1.00 & $(1.00-1.00)$ & 0.77 \\
\hline FFM, trunk (g) & 1.00 & $(1.00-1.00)$ & 0.90 & 1.00 & $(1.00-1.00)$ & 0.37 & 1.00 & $(1.00-1.00)$ & 0.52 \\
\hline BMC, upper limbs (g) & 1.00 & $(0.99-1.01)$ & 0.94 & 0.99 & $(0.99-1.00)$ & 0.87 & 1.00 & $(1.00-1.00)$ & 0.87 \\
\hline BMC, lower limbs (g) & 1.00 & $(1.00-1.00)$ & 0.85 & 1.00 & $(1.00-1.00)$ & 0.64 & 1.00 & $(1.00-1.00)$ & 0.79 \\
\hline BMC, trunk (g) & 1.00 & $(1.00-1.00)$ & 0.82 & 1.00 & $(1.00-1.00)$ & 0.75 & 1.00 & $(1.00-1.00)$ & 0.88 \\
\hline
\end{tabular}

Abbreviations: OR odds ratio, 95\% Cl 95\% confidence interval, \%FM relative fat mass, FM fat mass, BMC bone mineral content, FFM fat-free mass, BMD bone mineral density, NS non-significant

Table 4 Logistic regression comparing the non-injured group and groups with lower or upper limb injury

\begin{tabular}{|c|c|c|c|c|c|c|}
\hline \multirow[t]{2}{*}{ Non-injured group vs. group with lower limb injury } & \multirow[t]{2}{*}{ B } & \multirow[t]{2}{*}{ SE } & \multirow[t]{2}{*}{$P$} & \multirow[t]{2}{*}{ OR } & \multicolumn{2}{|c|}{ (95\% Cl OR) } \\
\hline & & & & & Lower & Upper \\
\hline Bone mass, left lower limb & -0.002 & 0.002 & 0.468 & 0.998 & 0.994 & 1.003 \\
\hline Bone mass, right lower limb & -0.002 & 0.002 & 0.403 & 0.998 & 0.993 & 1.003 \\
\hline Difference between the lower limbs & -0.005 & 0.011 & 0.673 & 0.995 & 0.975 & 1.017 \\
\hline Fat mass, left lower limb & 0.000 & 0.000 & 0.641 & 1.000 & 0.999 & 1.000 \\
\hline Fat mass, right lower limb & 0.000 & 0.000 & 0.599 & 1.000 & 0.999 & 1.000 \\
\hline Difference between the lower limbs & -0.001 & 0.002 & 0.701 & 0.999 & 0.996 & 1.003 \\
\hline Lean mass, left lower limb & 0.000 & 0.000 & 0.394 & 1.000 & 1.000 & 1.000 \\
\hline Lean mass, right lower limb & 0.000 & 0.000 & 0.390 & 1.000 & 1.000 & 1.000 \\
\hline Difference between the lower limbs & 0.000 & 0.001 & 0.946 & 1.000 & 0.999 & 1.001 \\
\hline Non-injured group vs. group with upper limb injury & B & SE & $P$ & OR & Lower & Upper \\
\hline Bone mass, left upper limb & 0.005 & 0.009 & 0.607 & 1.005 & 0.987 & 1.023 \\
\hline Bone mass, right upper limb & 0.005 & 0.009 & 0.576 & 1.005 & 0.988 & 1.023 \\
\hline Difference between the upper limbs & 0.008 & 0.033 & 0.801 & 1.008 & 0.944 & 1.077 \\
\hline Fat mass, left upper limb & -0.001 & 0.002 & 0.708 & 0.999 & 0.996 & 1.003 \\
\hline Fat mass, right upper limb & -0.001 & 0.002 & 0.602 & 0.999 & 0.995 & 1.003 \\
\hline Difference between the upper limbs & -0.002 & 0.005 & 0.723 & 0.998 & 0.990 & 1.007 \\
\hline Lean mass, left upper limb & 0.000 & 0.001 & 0.985 & 1.000 & 0.999 & 1.001 \\
\hline Lean mass, right upper limb & 0.000 & 0.001 & 0.991 & 1.000 & 0.999 & 1.001 \\
\hline Difference between the upper limbs & 0.000 & 0.002 & 0.979 & 1.000 & 0.996 & 1.004 \\
\hline
\end{tabular}


do not have epidemiologic data on other health problems in our study population, the incidence of MI in our study and previous epidemiologic studies in the literature can evidently justify the search for risk factors for MI.

With respect to the anatomical body parts affected, similar to our study, many studies have found a higher prevalence of injuries in the lower limbs. A Finnish study indicated a prevalence rate of $67 \%$ for lower limb injury in four cohorts followed up for 6 months [4], whereas another Finnish study reported a prevalence rate of $48 \%$ for lower limb injury in 944 conscripts who were followed up [3]. These results are consistent with those of our study, which showed that $69.7 \%$ of the injuries occurred in the lower limbs.

An interesting finding of our study is that sports experience prior to military service was a protective factor for MI, which is consistent with that of another military study [4]. According to Taanila et al. [4], previous experience of physical activity can produce overload on musculoskeletal structures prior to military service. In this case, we believe that previous physical activity programs can improve fitness and maturation of the musculoskeletal system. This could supposedly prepare participants for new training routines in the service, as the physical demands on them are lower than their less active counterparts. Such an idea was already previously proposed in the literature [23]. Moreover, this becomes evident in the study by Knapik et al. (2006) in which military low-fit recruits who participated in a pre-conditioning physical program before basic combat training tended to have a lower risk of injury during military service than low-fit recruits who did not participate in a pre-conditioning program [24].

This is particularly important for our study population, which was composed of students who supposedly had to spend part of their time studying for intelligence tests prior to military service. It is important to mention that, different from recruits, the military service as student in Escola Preparatória de Cadetes do Exército is not compulsory, and that before been considered approved to the service, participants underwent to a selection process composed by physical, health and intelligence test to be eligible.

However, it is important to mention that our main objective was to verify if anthropometric and body composition variables could be considered risk factors for MI. Despite our previous hypothesis, we could not identify any studied variables that could be considered risk factors for MI or overload or traumatic injuries. In this respect, no consensus on the relationship between body composition and anthropometric variables and the risk for MI exists in the literature.
Our hypothesis that anthropometric and body composition variables could be risk factors for MI was based on various previous studies. For example, in the military and athletic populations, higher BMI [3, 25], larger abdominal girth [3], and both low [26] and high body mass [27] were identified as risk factors for MI. Moreover, a high BMI was identified as a risk factor for MI in the lower limbs [28] and increased height was identified as a risk factor for MI [29]. Taking all these findings from previous studies into consideration, we formulated the hypothesis that body composition variables could also be risk factors for MI in our study population.

In contrast, although a small body of literature provides information on anthropometric variables as risk factors for MI, many studies that had the same objective refuted this hypothesis. For example, Rauh et al. observed that body mass, height, and BMI were not associated with incidence and risk of stress fractures or overload injuries in female recruits from the American Navy [30]. Moreover, some studies on athletes were not able to identify anthropometric variables as risk factors. For example, body mass was not considered a risk factor for MI in rugby athletes [31], and body mass, height, BMI, and body fat percentage measured by skinfold thickness were not identified as risk factors for MI in football athletes [32]. Consequently, the variability and inconsistency in results to date affect whether researchers can identify anthropometric variables as risk factors for MI.

Moreover, some studies sought to identify anthropometric variables as risk factors for specific injuries in militaries. Rauh et al. did not identify body mass, height, or BMI as a predictive factor for stress fractures [30] and Mahieu et al. did not also consider these variables as risk factors for calcaneus tendinopathy [33]. Further, Moen et al. did not identify body mass, height, BMI, maximal calf girth, and lean calf girth (maximal calf girth less calf skinfold) as risk factors for medial tibial stress syndrome [34].

Some hypotheses may potentially explain why our study, unlike other studies on militaries [3,25] did not find a relation between anthropometric and body composition variables and the risk for MI. Our study population comprised students who were recently approved in a selection process prior to military service, which consisted of an intelligence test, followed by health examination and physical fitness tests. The characteristics of our study population may have reduced the variability in body composition variables in the students who were the sample population because of the physical fitness requirements to be approved in the selection process, which likely made our study population quite homogenous compared to the recruit population 
followed up in other studies. A study identified higher BMI as a risk factor for MI in American male recruits [35]. However, the mean BMI of the population in the previous study was $24.3 \mathrm{~kg} / \mathrm{m}^{2}$, whereas the mean BMI of our study population was $22.9 \mathrm{~kg} / \mathrm{m}^{2}$. Moreover, the standard deviation for BMI was 4.85 and 2.1 in the previous study and our study, respectively. It is also important to mention that no minimal physical fitness requirements for the recruits at the beginning of compulsory military service usually exist in Brazil; in contrast, the students in our study voluntarily participated in the military selection process, which had physical requirements for approval.

With respect to tools used to evaluate anthropometric and body composition variables in the previous studies, most investigations had measured anthropometric variables using simple and unspecific tools, and studies often failed to evaluate body composition variables or distinguish lean mass, fat mass, or bone variables. No military studies apparently used DXA to measure body composition variables to identify risk factors for $\mathrm{MI}$ in militaries. All anthropometric variables evaluated by the different aforementioned studies to date included body mass, height, BMI, abdominal girth, body fat percentage measured by skinfold thickness, maximal calf girth, and lean calf girth. In this regard, some disadvantages of DXA may explain why there are few studies, even with athletes, with the same objective as our study, that have investigated similar variables by using DXA: it is expensive, often not accessible to study centres, and is not portable.

A careful literature search revealed that a few studies indeed have used DXA with the same objective as the present study [36, 37] and suggests that many other body composition variables should be further investigated. In this respect, we found three studies that followed up athletes. Interestingly, of these three studies, only one identified body composition variables as risk factors. In this study, lower BMD, lower lean mass, lower bone (tibial) mass, higher fat mass, and higher body mass were associated with bone injuries [19]. The other two studies were not able to identify risk factors for stress fractures in cross-country athletes [36], and vertebral fractures in rugby athletes [37].

DXA continues to be considered the gold standard for evaluating BMD, being a non-invasive method that involves low radiation exposure, and demonstrates good accuracy with respect to total or segmental body composition evaluation [38].

However, aside from the advantages of the method, the fact that we could not find studies that used DXA to identify risk factors for MI in the militaries clearly indicates the current need for more studies adopting DXA with the same objective, preferably with a large sample of injured participants.
The small sample of injured participants can be considered a limitation of the present study, considering that there are previous studies with larger samples of significantly injured participants $[3,4]$, which gives them a higher statistical power for observing risk factors.

Furthermore, it would be interesting to register the severity of injuries as training days lost per injury, which would permit statistical analyses in groups categorized by severity. Finally, the cross-sectional design of body composition evaluation did not permit us to identify how body composition changed during military training. Thus, a no one-time point future study would be interesting.

However, considering the several strong points of this study and its results, and the evident variability of results found in the literature to date, this indicates the need for the identification of other intrinsic and extrinsic variables as risk factors. Our findings cannot confirm the relation between anthropometric and body composition variables and the risk for MI during military service.

\section{Conclusion}

MI is an important public health problem that causes premature discharge from military service; $30 \%$ of our study population presented with MI. Lower limb injuries were the most prevalent, mainly ankle sprain and medial tibial stress syndrome. Overload injuries were more prevalent than traumatic injuries. It was not possible to establish the relationship between anthropometric or body composition variables and risk for MI during military service in this population with the current sample size. However, future studies with data collected over multiple time-points or with more individuals may identify patterns of injury risk.

\section{Abbreviations}

BMC: Bone mineral content; BMD: Bone mineral density; BMI: Body mass index; DXA: Dual-energy X-ray absorptiometry; MI: Musculoskeletal injuries

\section{Acknowledgments \\ The present study was developed at Escola Preparatória de Cadetes do Exército. We appreciate the excelent cooperation of the personnel of that military school over the course of the study and also thank EsPCEx commandant.}

\section{Availability of data and materials}

The datasets used and/or analyzed during the current study are available from the corresponding author on reasonable request.

\section{Authors' contributions}

MASM, JAA, MAP, CJOB, VXC, EMG and GGJ contributed to all data analysis, interpretation and data acquisition. All authors made intellectual contribution to the study and reviewed the article. All authors read and approved the final manuscript.

\section{Ethics approval and consent to participate}

The present study received the local Ethic comittee approval and the consent from all participants was obtained via signed written document. Local Ethic committee approval number: Comitê de ética em Pesquisa Universidade Estadual de Campinas: 5114610. 


\section{Consent for publication}

Not applicable

\section{Competing interests}

The authors declare that they have no competing interests.

\section{Publisher's Note}

Springer Nature remains neutral with regard to jurisdictional claims in published maps and institutional affiliations.

Received: 21 March 2018 Accepted: 3 October 2018

Published online: 17 October 2018

\section{References}

1. Mehri NS, Sadeghian M, Tayyebi A, et al. Epidemiology of physical injuries resulted from military training course. Iran J Military Med. 2010;12(2):89-92.

2. Kaufman KR, Brodine S, Shaffer R. Military training-related injuries. Surveillance, research, and prevention. Am J PrevMed. 2000;18(3S):54-63.

3. Taanila $H$, Suni J, Pihlajamaki $H$, et al. Aetiology and risk factors of musculoskeletal disorders in physically active conscripts: a follow-up study in the Finnish Defence Forces. BMC MusculoskeletDisord. 2010;11:146.

4. Taanila H, Suni JH, Kannus P, Pihlajamaki H, Ruohola JP, Viskari J, Parkkari J. Risk factors of acute and overuse musculoskeletal injuries among young conscripts: a population-based cohort study. BMC Musculoskelet Disord. 2015;16:104.

5. Taanila H, Hemminki AJM, Suni JH, Pihlajamaki H, Parkkari J. Low physical fitness is a strong predictor of health problems among young men: a follow-up study of 1411 male conscripts. BMC Musculoskelet Disord. 2011; 11:590.

6. Grier T, Canham-Chervak M, McNulty V, Jones BH. Extreme conditioning programs and injury risk in a US army brigade combat team. US ArmyMedDep J. 2013;36-47.

7. Kuikka PI, Pihlajamaki HK, Mattila VM. Knee injuries related to sports in young adult males during military service - Incidence and risk factors. Scand J Med Sci Sports. 2013;23:281-7.

8. Havenetidis K, Paxinos T. Risk factors for musculoskeletal injuries among Greek Army Officers Cadets undergoing basic combat training. Mil Med. 2011;176(10):1111-6.

9. Pietrobelli A, Andreoli A, Cervelli V, Carbonelli MG, Peroni DG, De Lorenzo A Predicting fat-free mass in children using bioimpedance analysis. ActaDiabetol. 2003:40(Suppl. 1):S212-S15.

10. Nielsen BM, Dencker M, Ward L, Linden C, Thorsson O, Karlsson MK, et al. Prediction of fat-free body mass among 9- to 11-year-old Swedish children. Diabetes. ObesMetab. 2007;9:521-39.

11. Kriemler S, Puder J, Zahner L, Roth R, Meyer U, Bedogni G. Estimation of percentage body fat in 6- to 13-year-old children by skinfold thickness, body mass index and waist circumference. Br J Nutr. 2010;104:1565-72.

12. Albanese CV, Diessel E, Genant HK. Clinical applications of body composition measurements using DXA. J ClinDensitom. 2003:6:75-85.

13. Stewart AD, Hannan WJ. Prediction of fat and fat-free mass in male athletes using dual X-ray absorptiometry as the reference method. J Sports Sci. 2000;18(4):263-74

14. Santos DA, Dawson JA, Matias CN, Rocha PM, Minderico CS, Allison DB, Sardinha LB, Silva AM. Reference values for body composition and anthropometric measurements in athletes. PLoS One. 2014;9(5):e97846. https://doi.org/10.1371/journal.pone.0097846. eCollection 2014.

15. Langer RD, Borges JH, Pascoa MA, Cirolini VX, Guerra-Júnior G, Gonçalves EM. Validity of Bioelectrical Impedance Analysis to Estimation Fat-Free Mass in the Army Cadets. Nutrients. 2016;8(3):121.

16. Mazess RB, Barden HS, Bisek JP, Hanson J. Dualenergy X-ray absorptiometry for total-body and regional bonemineral and soft-tissue composition. Am J ClinNutr. 1990;51:1106-12

17. Svendsen OL, Haarbo J, Hassager C, Christiansen C. Accuracy of measurements of body composition by dual energy X-ray absorptiometry in vivo. Am J Clin Nutr. 1993:57:605-8.

18. Mattsson S, Thomas BJ. Development of methods for body composition studies. Phys Med Biol. 2006:51:203-28.

19. Georgeson EC, Weeks BK, McLellan C, Beck BR. Seasonal change in bone, muscle and fat in professional rugby league players and its relationship to injury: a cohort study. BMJ Open. 2012;2:e001400.
20. Silva A, Zanca G, Alves ES, Lemos VA, Gávea SA, Winckler C, Mattiello SM, Peterson R, Vital R, Tufik S, De Mello MT. Isokinetic assessment and musculoskeletal complaints in Paralympic athletes. Am J Phys Med Rehabil. 2015:0:1-7.

21. Freckleton $\mathrm{G}$, Cook J, Pizzari $\mathrm{T}$. The predictive validity of a single leg bridge test for hamstring injuries in Australian Rules Football Players. Br J Sports Med. 2014;48:713-7.

22. Taanila H, Hemminki AJM, Suni JH, Pihlajamaki H, Parkkari J. Low Physical Fitness is a strong predictor of health problems among young men: a follow-up study of 1411 male conscripts. BMC Public Health. 2011;11:590.

23. Jones BH, Thacker SB, Gilchrist J, Kimsey JRCD, Sosin DM. Prevention of lower extremity stress fractures in athletes and soldiers: a systematic review. Epidemiol Rev. 2002;24(2):228-47.

24. Knapik JJ, Darakjy S, Hauret KG, Canada S, Scott MAJS, Reger W, Marin R, Jones $\mathrm{BH}$. Increasing the physical fitness of low-fit recruits before basic combat training: an evaluation of fitness, injuries, and training outcomes. Mil Med. 2006;171(1):45-54.

25. Grier T, Canham-Chervak M, McNulty V, Jones BH. Extreme conditioning programs and injury risk in a US Army Brigade Combate Team. Army Med Depart J. 2013:36-47.

26. Gastin PB, Meyer D, Huntsman E, Cook J. Increase in injury risk with low body mass and aerobic-running fitness in elite Australian football. Int J Sports Physiol Perform. 2015;10:458-63.

27. Gabbett TJ, Ullah S, Finch CF. Identifying risk factors for contact injury in professional rugby league players - Application of a frailty model for recurrent injury. J Sci Med Sport. 2012:15:496-504.

28. Nilstad A, Anderson TE, Bahr R, Holme I, Steffen K. Risk factors for lower extremity injuries in elite female soccer players. Am J Sports Med. 2014;42(4):940-8.

29. Faude O, Junge A, Kindermann W, Dvorak J. Risk factors for injuries in elite female soccer players. Br J Sports Med. 2006:40:785-90.

30. Rauh MJ, Macera CA, Trone DW, Shaffer RA, Brodine SK. Epidemiology of stress fracture and lower-extremity overuse injury in female recruits. Med Sci Sports Exerc. 2006;38(9):1571-7.

31. Fuller CW, Caswell SE, Zimbwa T. Do mismatches between teams affect the risk of injury in the rugby world cup? J Sci Med Sport. 2010;13:36-8.

32. Haxhiu B, Murtezani A, Zahiti B, Shalaj I, Sllamniku S. Risk factors for injuries in professional football players. Folia Med. 2015;57(2):138-43.

33. Mahieu NN, Witvrouw E, Stevens V, Van Tiggelen D, Roget P. Intrinsic risk factores for the development of Achilles tendon overuse injury: a prospective study. Am J Sports Med. 2006;34(2):226-36.

34. Moen MH, Bongers T, Bakker EW, Zimmermann WO, Weir A, Tol JL, Backx FJG. Risk factors and prognostic indicators for medial tibial stress syndrome. Scand J Med Sci Sports. 2012:22(1):34-9.

35. Jones BH, Bovee MW, Harris JM III, Cowan DN. Intrinsic risk factors for exercise related injuries among male and female army trainees. Am J Sports Med. 1993;21(5):705-10.

36. Roelofs EJ, Smith-Ryan AE, Melvin MN, Wingfield HL, Trexler ET, Walker N. Muscle size, quality, and body composition: characteristics of division cross-country runners. J Strength Cond Res. 2015:29(2):290-6.

37. Hind $K$, Birrell F, Beck B. Prevalent morphometric vertebral fractures in professional male rugby players. PLoS One. 2014;9(5):e97427.

38. Lee SY, Gallagher D. Assessment methods in human body composition. CurrOpinClinNutrMetab Care. 2008;11(5):566-72.

Ready to submit your research? Choose BMC and benefit from:

- fast, convenient online submission

- thorough peer review by experienced researchers in your field

- rapid publication on acceptance

- support for research data, including large and complex data types

- gold Open Access which fosters wider collaboration and increased citations

- maximum visibility for your research: over $100 \mathrm{M}$ website views per year

At BMC, research is always in progress.

Learn more biomedcentral.com/submissions 